\title{
The Conjugation Method of Augmented Reality in Museum Exhibition
}

\author{
Hee-soo Choi \\ Department of History, Sangmyung University, \\ 7 Hongji-dong, Jongno-gu, Seoul, Korea(110-743) \\ choice@smu.ac.kr
}

\begin{abstract}
In the age of digital convergence, examples of digital convergence are often witnessed in all aspects of society. Particularly worthy of note among them is the development of a technology called augmented reality $(A R)$, which are aimed at pushing the limits of human experience. This has laid the foundation for new cultural conditions by manipulating the existing conditions of human experience. Especially, mobite is actively used as ubiquitous service that surpasses the limit of time and space. And it gives the people wanted information. Technologies like this are applied to exhibition at museums. AR technology has a wide range of applications, and can be effectively applied o museum exhibit environments, should the need arise for information on the uses and functions of artifacts, information on the restoration of damaged artifacts, the spatial characteristics of artifacts, or objects that require the modernization of artifacts. Utining AR technology via mobile applications can be implemented with no additional meed for hardware and system. Augmented reality (AR) technology can provide a variety of Solutions to help museums fulfill their role and goals..
\end{abstract}

Keywords: Digital convergence, augmented reality, museum, exhibition content, experience (experiential elements)

\section{Development of Cultural Technology in the Age of Digital Convergence}

Today's society has entered the age of digital convergence. In other words, digital convergence has become the driving force behind social development. Digital convergence is now the backbone of our society, and their development has lately been remarkably successful. The technology has allowed people to reconstruct reality to push the limits of perceived human experience. Augmented reality (AR) has helped reach beyond the limits of people's perceived natural environment by breaking down the boundaries between the virtual and real worids.

Such d gital technologies represent a radical change in the conditions under which human experience is created. The conditions of human experience that are created and developed are cultura. The change in the conditions of human experience caused by digital technologies is simulaneously a cultural one as well. The argument is therefore convincing that, once these technologies blur the boundaries between virtual and real, the new reality created by the collapse of the virtual-real boundaries changes the patterns of human behavior, thereby giving rise to new cultural conditions. ${ }^{1}$

\footnotetext{
${ }^{1}$ Lee Jong-gwan, Park Seung-eok, Kim Jong-gyu, Im Hyeong-taek: Philosophical Reflections on Convergence Technology in the Digital Cultural Industry. Research on Future Platforms for Digital Convergence II. Korea Information Society Development Institute(2010.12)
} 
The augmented reality is the most widely used technology among the digital convergence and changes the environments of human experience dramatically. ${ }^{2}$ This mixes reality with virtual world, so the contents could be known intuitively. Augmented reality technology makes people to experience the virtual world in reality, and it contributes to increasing intellectual capacity of human in various fields, such as education, exhibition or tourism.

This presentation discusses the applications of augmented reality in museum ${ }^{3}$ exhibit environments. Since museum exhibitions are under greater spatiotemporal constraints than any other environment, they urgently need digital technologies that allow the augmentation of visitors' experiences. This presentation examines how augmented reality can overcome the spatiotemporal limits of museum exhibit settings and bridge the gap in cultural perception that spectators may have while appreciating artifacts of different time periods.

\section{Functions of Museums and the Need for Advanced Technology}

In the conventional sense of the word, 'museum' means a building deyoted to the collection and exhibition of objects of inquiry, research, and appreciation the key focus here lies on 'exhibition'. 'Exhibition' is the act of appraising and evaluating collected objects, making them accessible to visitors, and drawing interest among researchers and investigators. Developing models of museum are classified by the methods of exhibition. Following pictures show that various models of museum are found according to the methods of exhibition.

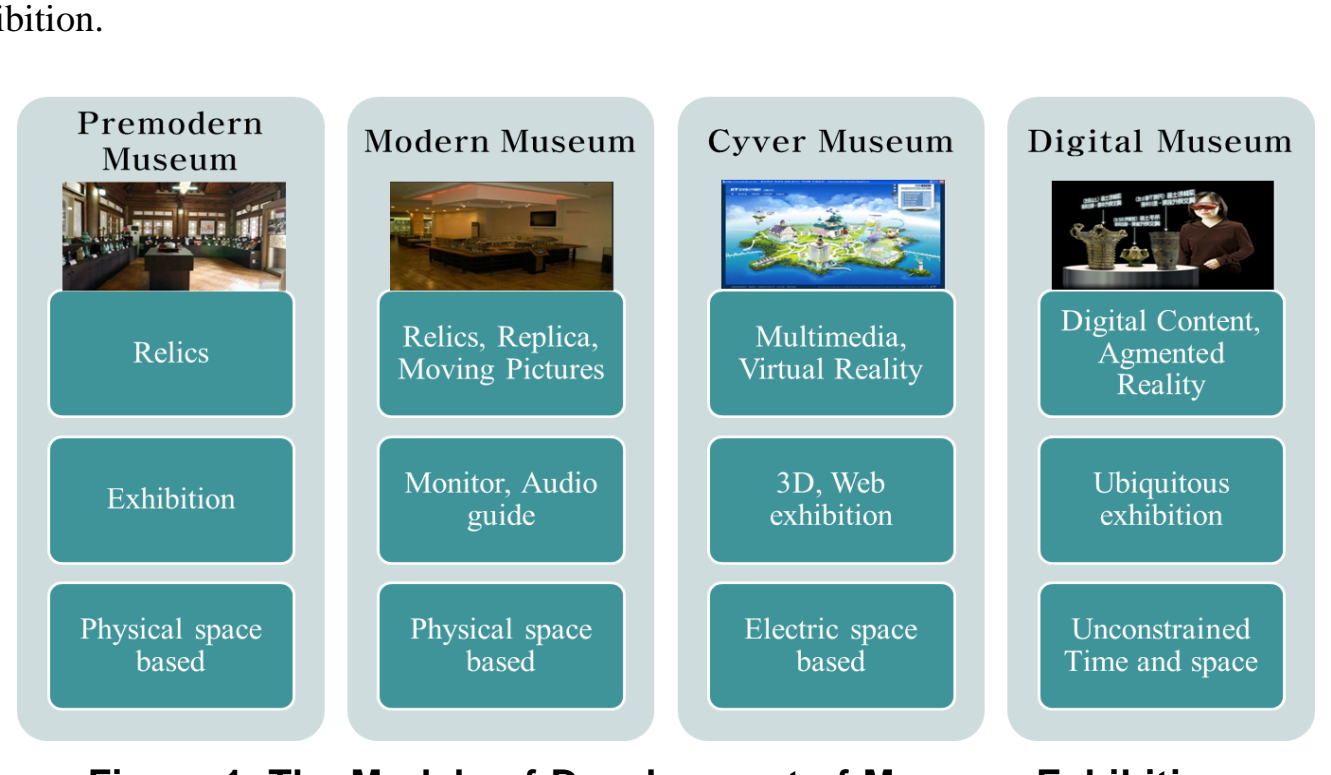

Figure 1. The Models of Development of Museum Exhibition

\footnotetext{
${ }^{2}$ There are three types of digital technology that provide the environments of human experiencevirtual reality, augmented reality, and mixed reality. The differences among these three are as follows: Virtual reality refers to a computer-simulated environment, which can simulate a physical existence in the real or virtual world. The virtual reality environment can be expressed on a computer screen or a three-dimensional display. Augmented reality is an environment augmented by computer-generated sensory input on a video image of the real world, such as graphics, sounds, and GPS data, and allows an observed reality to be computer-modified or augmented. Lastly, mixed reality encompasses all augmented environments on the reality-virtual continuum between the real and virtual worlds. The reality-virtual continuum exists in all variations of augmented reality and augmented virtual.

${ }^{3}$ The museums here refer to historical museums that display historical artifacts.
} 
Modern museum added models, replicas, and moving exhibits to pre-modern museum, so visitors could get more information. Physical displaying space is precondition for pre-modern museum and modern museum. However, for cyber museum that added multimedia and virtual reality according to development of IT, CT technologies, electrical displaying space is more important than physical displaying space. Especially from cyber museum model, experience elements that prompting visitors' five senses are regarded as important.

As digital technologies related networks and sensors are becoming common, ubiquitous service has been developed. This phenomenon is applied to museum intactly. It means ubiquitous service that overcoming the limit of time and space, and providing personalized service is applied to museum. Digital museum is the museum with these technologies.

In the digital museum model, various efforts are progressed to accomplish the ubiquitous services. At first, information about artifact was provided through portable device and IR sensor. Next, the information about artifact was provided through RFID tag and portable device. Recently museum efforts peoples' satisfaction, they emplaced media table and media wall which has been using sensors and multi-touch technologies. However, this method has several limits. For example, the sensors working area is limited. Also, the devices are very expensive. On the other hand, the hardware is difficult to maintenance.
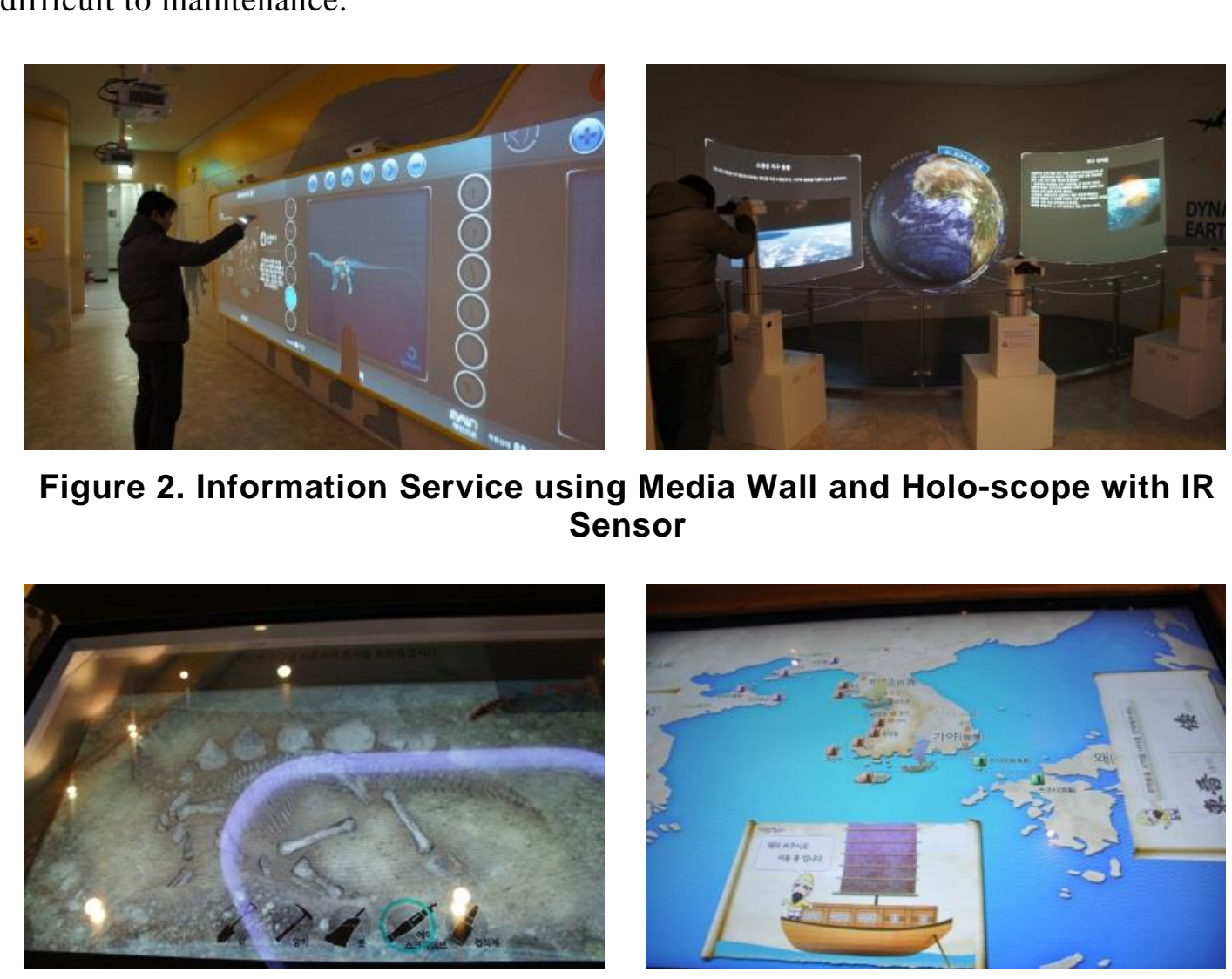

Figure 3. Information Service using Media Table with Touch Screen 

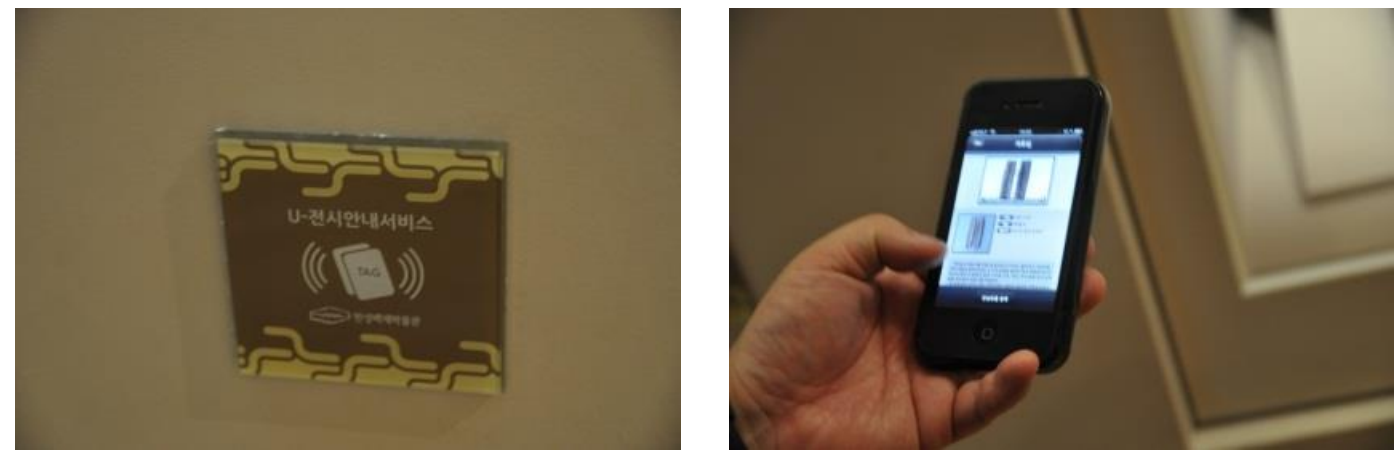

Figure 4. Information Service using the Mobile Application with RFID Tag

Nowadays smartphones have propagated widely in the world. Mobile service using smartphones is chosen actively, because people can get the information at anywhere with communications network. So, AR with cameras installed smartphones is used widely. Like this way, various digital contents and cultural technologes could be used in museum exhibition. This means the evolution to digital museum which is the most efficient and developmental model among the development models of museum.

As stated above, essential factor in developing models of museum is the method of exhibition and expansion of experience elements through the method. The criteria of a good museum is its exhibition method. Museums, therefore, adopt a variety of exhibition techniques to provide good exhibitions. In the past, museums merely arranged the objects they deemed important in showcases. However, they started using dioramas to help understand the cultural contexts of artifacts, for example, by recreating their historical settings, with the advancement of digital technologies, museums have also begun to apply IT to theirexhibitions.

There are several factors to consider for making a good exhibition, but the most important factor is exhjbition design. Several virtues of exhibition design are needed to maximize the function of museum According to Carliner, among others there are 10 must-dos for successful museun exhibit design. ${ }^{4}$ The elements which can be addressed by the use of technology include. motivating and intriguing the visitors, implementing focus contents, engaging the viewers by mutual interaction, immersing them within exhibition spaces. Mos popular example is the audio-guide system that provides the visitors with recorded spoken commentaries through the headsets or smartphones. However, they serve a limited role as substitutes for docents and do not fully satisfy the aforementioned 10 elements of successful exhibition.

\footnotetext{
${ }^{4}$ WHAT MUSEUMS MUST DO - The following are 10 ingredients for successful museum exhibit design: (1. Motivate Visitors: Target an audience - the general public and/or specific communities, 2. Focus Content: Filter content so visitors are not bombarded with information overload, 3. Immersion: Engage visitors with in a "story", 4. Modularity: Present smaller themes instead of one larger complex topic, 5. Skimmability: Information should be easy to take in because visitors are often standing and/or have different levels of education, 6. Patterns: Incorporate traffic/circulation patterns, exhibit sequence patterns and pre-existing framework patterns (architectural elements), 7. Capture Curiosity: Use storytelling techniques to engage visitors, 8. Interaction: Give visitors a "fun" experience by tapping into their emotion, 9. Integrate Technology: Technology should enhance visitor's experience, not distract from it, 10. Layer Content: Present information in a hierarchical manner(Carliner, Saul: Modeling Information for Three-Dimensional Space- Lessons Learned from Museum Exhibit Design. Models, Processes, and Techniques of Information Design, 2000).
} 
The previous studies have been focusing on how to immerse the visitors, because we have thought that the level of immersion is the most important factor that determines their perception of exhibited artifacts. However, the implementation of such exhibition technology seems to rather defeat the purpose by distracting the viewers' attention from the artifacts to the visual aspects of technology. The museum technology should serve the purpose of its exhibition that is to help the viewers to perceive the historical and cultural value of presented artifacts.

In addition, while many studies have taken a general approach to the subject of utilization of technology in museum exhibition space, there are only few that propose an approach more specific as to the types of technology to be employed for different types of presented artifacts.

As shown above, the key must-dos of museum exhibition design include motivating visitors, creating focus content, encouraging the engagement of visitors, sparking their curiosity, interaction, and technology integration. The digital technologies to be applied to museum exhibitions, therefore, have to meet these requirements. Museums have to reach their ultimate goals by helping visitors understand the historical cultural values of exhibits and sparking their curiosity through motivation immersion, and interaction.

Once again, museums should aim at overcoming the temporal limitations of artifacts, namely, the objects of exhibitions, the spatial (estrictions resulting from the spatial characteristics of exhibitions, and cultural differences that visitors will perceive. This explains the tendency of museums to utilize digital technologies to incorporate all sorts of experiential elements in order to overcome those spatiotemporal limits.

To push the spatiotemporal limits of museums is to change the conditions of experience of visitors. In other words, one of the most pressing tasks facing museums today is to overcome the spatial restrictions of museums and the temporal limitations of the artifacts displayed irrespective of their parposes and return artifacts to their original time periods and spaces. That is where augmented reality comes in: augmented reality tears down the barrier between the real and virtual worlds and let visitors experience the real temporal and spatral settings where artifacts originate. The varying features of augmented reality can be applied to a range of exhibits in museums. What follows are a few examples of augmented reality at a level where visitors can easily understand the uses and functions of artifacts, and those of augmented reality that allow a comparison of then and now.

\section{Types of Artifacts Context Information in Museum}

There are a few types of information that visitors can verify by looking at exhibits in museums. Depending on the context of exhibits, namely, the kind of content that visitors are supposed to understand and experience, these types of information can be summarized as follows. If 1 An artifact has certain uses and functions; 2 . The artifact has artistry in itself; 3. The artifact reflects the zeitgeist of a certain time period; 4 . The artifact is incomplete (needs to be restored); 5 . The original spatial configuration of an artifact is important; and 6. The detains of the artifact need to be modernized.

AR is able to apply all artifacts. However, if context is able to convey better than AR, it is not necessary to apply AR. Number 2 and 3 are the case of that. In a number 2 case, a artifact has remarkable artistic value like Koryo Celadon in Korea. The information of producing processes and outstanding colors of Koryo Celadon could be provided with AR, but specific explanation of docent or audio guide would be more effective. 
In case number 3, a artifact has social background or historical background. For example, Chulmun Pottery in the Neolithic era or Ground stone tools has a meaning itself, but also it could be used to report the way of life of people who lived at that time. Therefore, showing the way of life at that time and restoring Hut with the forms like diorama would be more important than using AR.
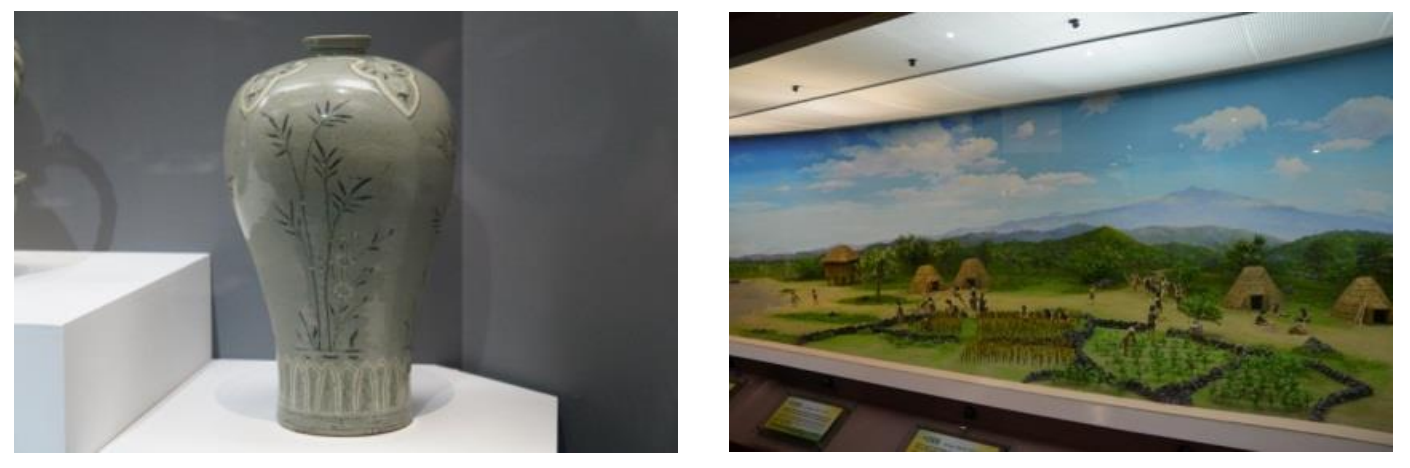

\section{Figure 5. Koryo Celadon(left), Life of the Neolithic people(right)}

Of these six cases, augmented reality can be applied to 1, 4, 5, and 6 . Let us take a look at each of them. First, an artifact has certain uses and functions. Examples are artifacts of the Stone Age, including stone axes, stone knives, stone arrowheads, stone finishing net sinkers, and pottery. Since these artifacts are usually placed in snowcases, they require explanations about how to make and use them. Most museums only provide additional explanations or brief descriptions for visitors to check the uses and functions of artifacts. While such methods help visitors understand the uses and functions of artifacts to a certain extent, visitors fail to get further details.
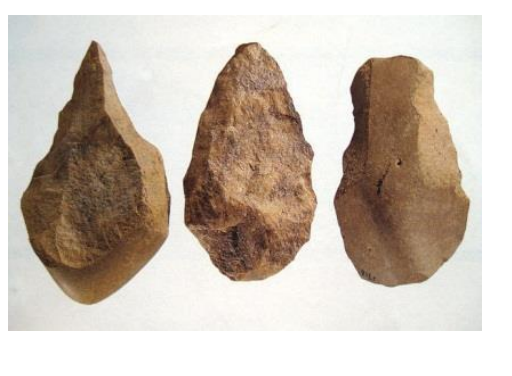

Hand axe in Yonchon, Korea (Hand axe, kind of chipped sone implement in the Paleolithic era. It is hard to know how it was made and how it was used by watching the display of artifacts.)

Second, the artifact is incomplete. There are important artifacts whose shapes have been so damaged over time that they are hardly recognizable. Those artifacts are displayed either as they are oralong with graphic panels that display their original forms. Visitors find it difficult to accurately identify the actual shapes of those artifacts because they have to move their eyes between the actual artifact and the graphic image of it restored version. Augmented reality should be used to project a restored image of an artifact onto the actual one.

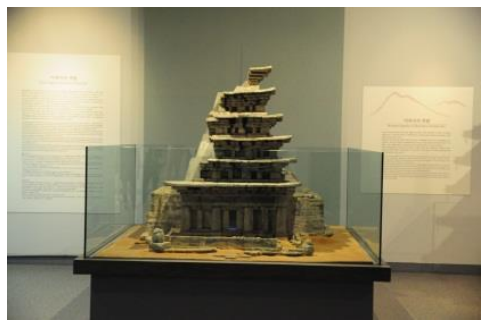

The stone pagoda at Mireuksa Temple in Korea (Stone pagoda made in Baekje. A considerable portion of stone pagoda is damaged. People couldn't know what was the original pagoda with current form.) 
Third, the original spatial configuration of an artifact is important. In other words, an artifact exists in a certain part of a larger structure, either as an ornament or as a tomb artifact. Such objects are exhibited together with a graphic panel that gives an image of the entire structure, a description of parts where the artifact in question was used, and, if a tomb artifact, a model of the tomb to provide details. However, such exhibit design poses a costly challenge and spatial limitations, especially if models are to be developed.

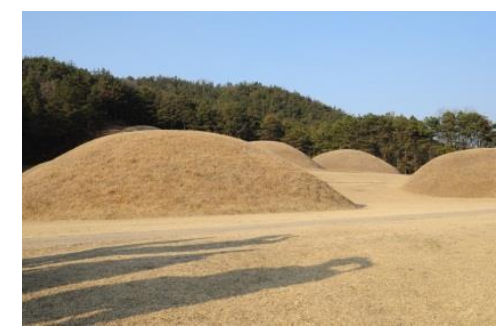

Tomb site in Neungsan-ri, Puyo, Korea(Tombs of Kings made in Baekjae era. People couldn't know its inner structures and what artifacts were inside of the tombs.)

Fourth, the details of an artifact need to be modernized The crux of the matter here is to bridge cultural differences. Most artifacts that fall under this category are in ancient writing and therefore need to be modernized to help contemporay spectators understand. Examples include ancient books, ancient documents, and aftifacts containing ancient scripts. Such exhibits come with additional descriptions for visitors convenience.

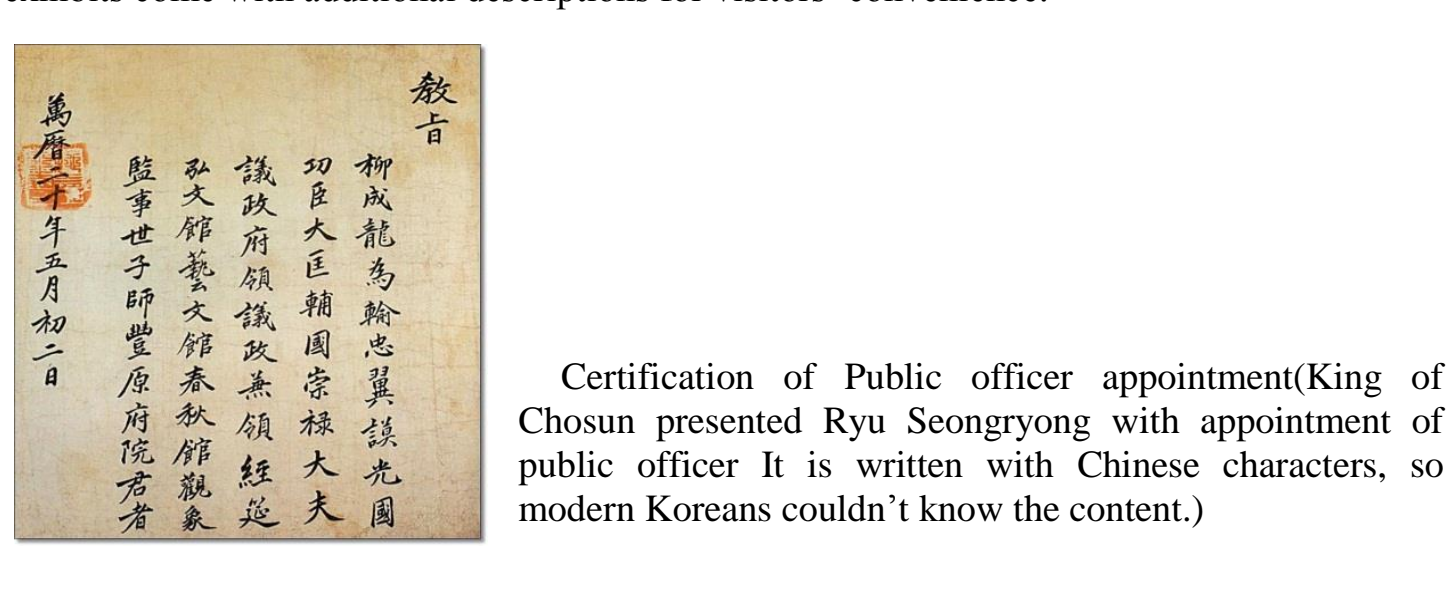

Next chapter contains information about the way that realizing context of this kind of exhibited artifacts by mobile Augmented Reality.

\section{How to Apply Augmented Reality to Museum Exhibitions}

As aforementioned, there are several types of artifacts. Following text is about the way that applying AR to the museum exhibition.

\subsection{Type that Needs Explanation of Artifacts' Use and Function}

The left image shows pottery exhibited in Shaanxi History Museum in Xi'an, China, and its description. The pottery alone would not be able to grab visitors' attention. The graphic panel that illustrates pumping water offers visitors a clear understanding of the use of the pottery. Furthermore, the mobile application allows visitors to display the pumping image on their smartphones by pointing their phones at the panel. Visitors can enjoy a whole new experience beyond the spatiotemporal limits of the pottery as a museum exhibit when this 
augmented reality enables the experience of actually watching someone pump water from a river in prehistoric times.
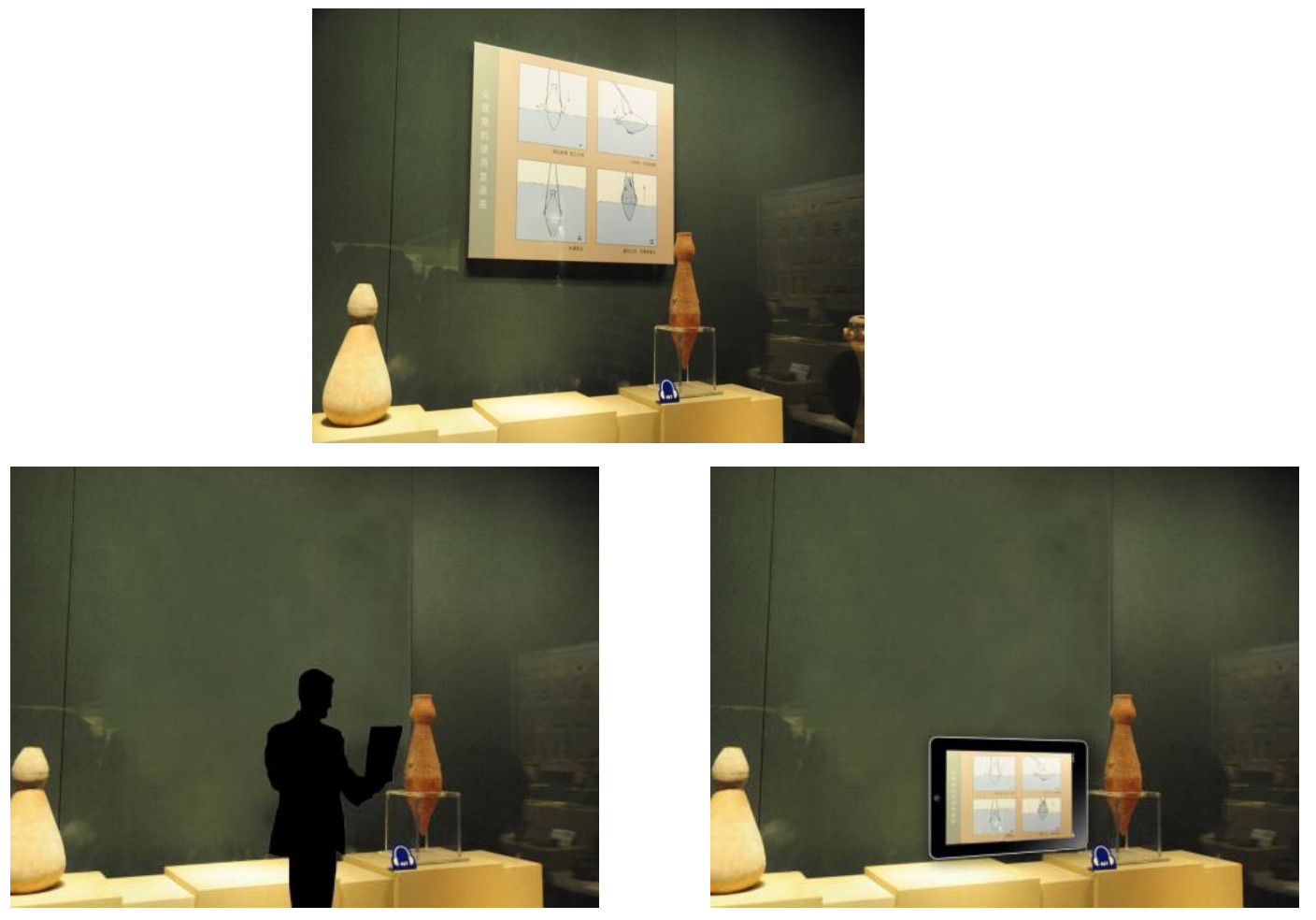

Figure 6. AR Information Service about Explanation of Artifact's Use and Function

\subsection{Type that Needs Restoration of Incomplete Artifacts}

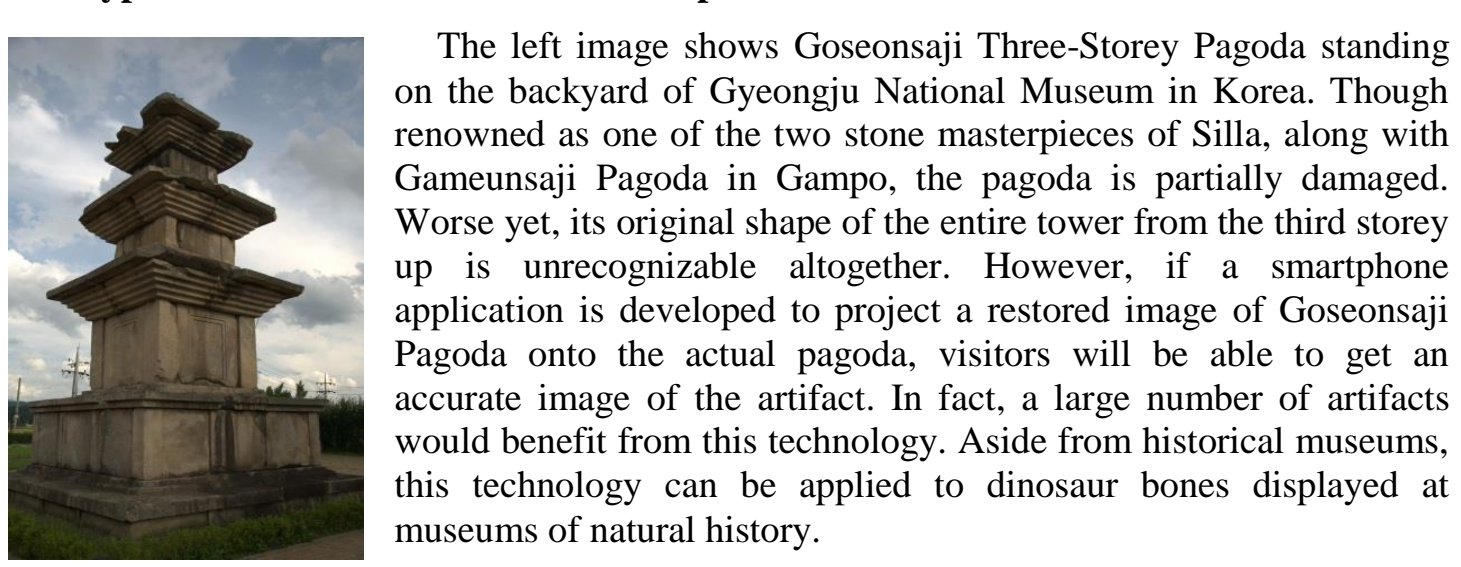



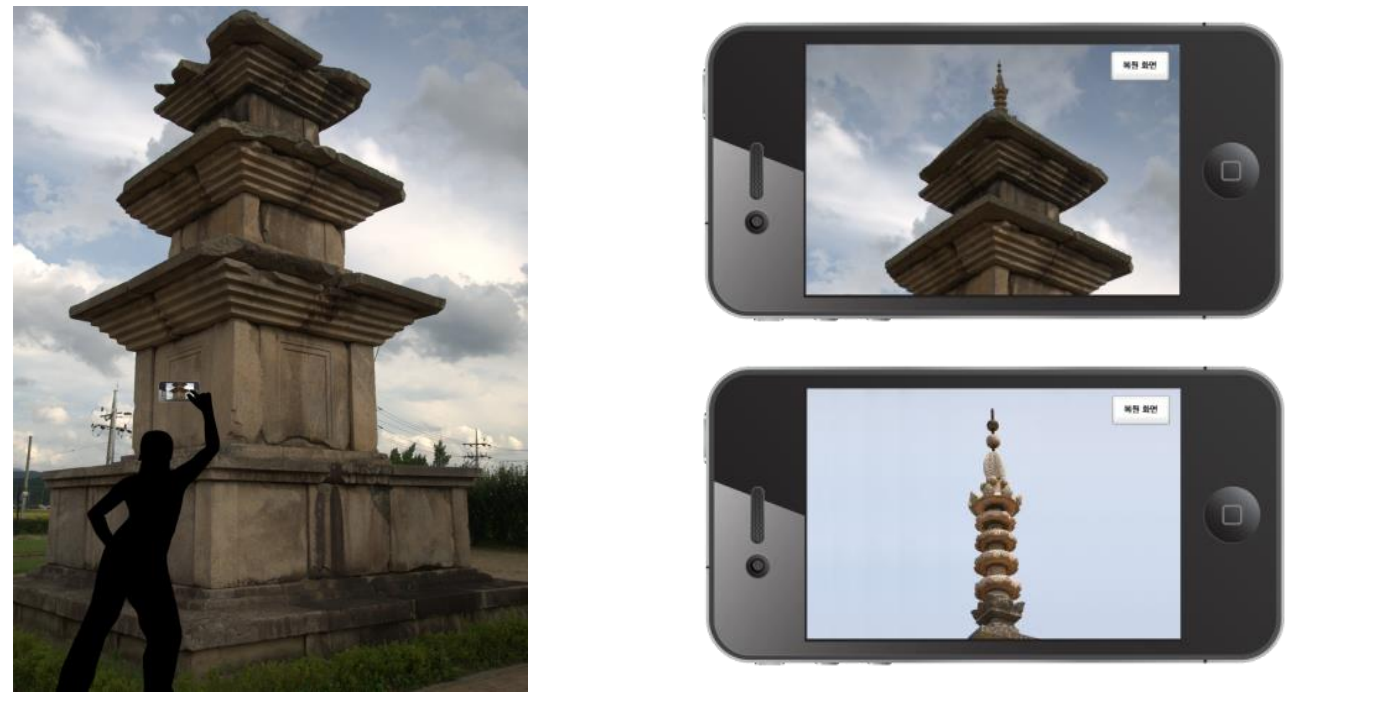

Figure 7. AR Information Service about Digittal Bestore

\subsection{Type that Needs Whole Structure with Artifact \\ The right picture is a graphic image that describes} the used part of the Cheonmado jangni (pad or blanket) at the Gyeongju National Museum and its uses. Next to the exhibit is a restored model of the actual jangni (a device mounted under a saddle to prevent mud splatter) with Cheonmado painted on it. When visitors look at Cheonmado, they would have no idea where the device was used, of where it was supposed to be during horseback riding. Now, the graphic panel mounted on the showease. By applying augmented reality, spectatorscan access the details

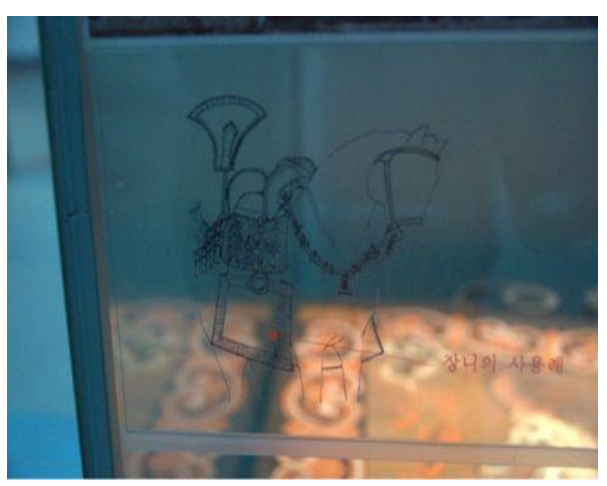
of Cheonmado right away.
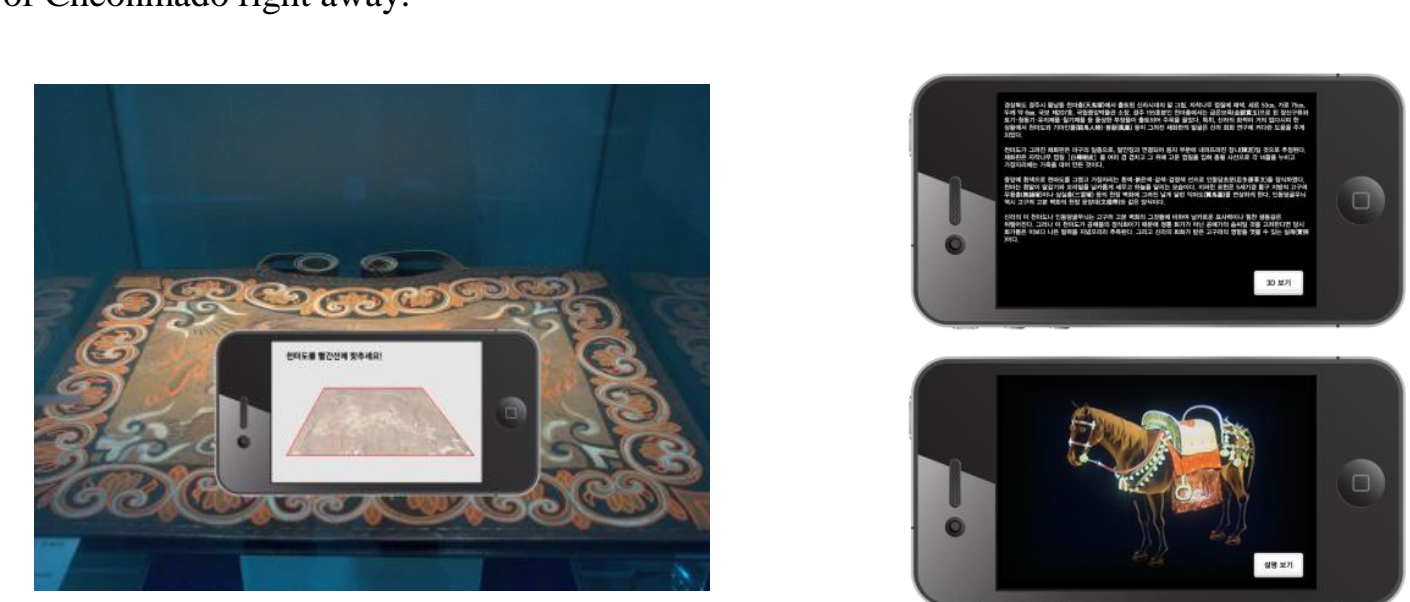

Figure 8. AR Information Service about Explanation and Structure 


\subsection{Type that Needs Modernization of Artifact Content}

The right image represents the dice excavated from Anapji and now displayed at the Gyeongju National Museum. The dice was supposedly made by Silla aristocrats for entertainment purposes, and contains the inscribed rules of punishment on each side of it. The rules are, however, all in Chinese characters and hard for visitors to easily comprehend. There is only a brief description of them next to the dice. A smartphone application using augmented reality will be able to recreate the rules engraved on the sides of the dice in modern writing. Using the smartphone technology to create a dice game in a realistic setting will add experimental elements and help bridge the cultural differences between Silla and contemporarypeople.

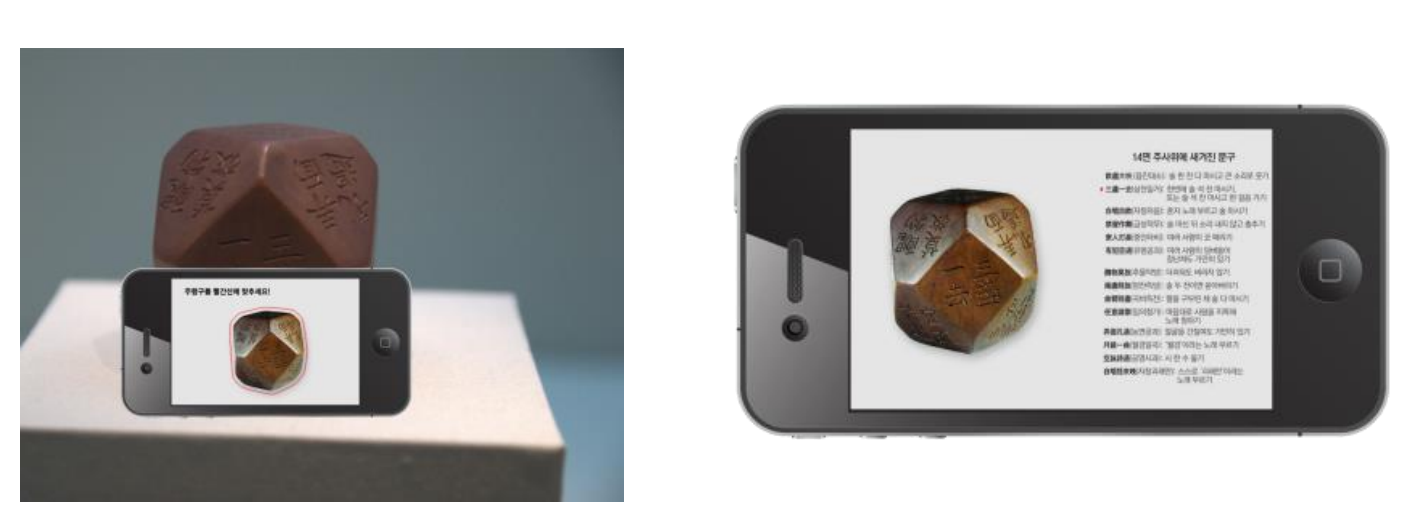

\section{Figure 9. AR Information Service about Modernization of Old Character \\ 5. Prospects of Merging Museum Exhibition and Digital Technology}

In this article, the contexts tha artifacts in museum have are classified, and the realization ways of AR for each context are found. Each artifact has different context. Digital technologies are needed to apply according to the type of context.

Digital technology is mos effective for visual presentation. To go beyond the image of an artifact, providing multimedia presentation featuring the historical and human environments in which the artifact was used - hence giving the artifact its context - makes imprints on the memory of the visitors more powerful than when the presentation was with audio text only.

Making the best use of digital technology is the latest trend among museum. In particular, high-tech media has become a popular approach, including 3-D hologram and interactive exhibit content using media tables, markers, and sensors, which provide a variety of experiential elements.

The use of high-tech media, however, requires hardware elements, namely, the medium itself and its enabling system. Museums are forced to make room for hardware installations in their exhibition space, adding further spatial constraints. Another drawback of hard-ware oriented technology is that it is short-lived, quick to be outdated due to rapid development in the IT field.

On the other hand, as discussed in this presentation, augmented reality technology can be realized using digital devices that individual museums retain, without having to procure software and additional devices for artifacts. The exhibition content created through 
augmented reality not only enables visitors to freely move around but also facilitates onesource multi-use. The content produced for each artefact can be used as it is when creating an interactive exhibition content system like a cyber museum or media table. Now, exhibition content can be viewed from places other than inside the museum with mobile applications. In conclusion, augmented reality is an ideal combination of museum exhibition and digital technology that meets the needs of this 'ubiquitous age'.

\section{Acknowledgements}

This research was supported by a 2013 Research Grant from Sangmyung University.

\section{References}

[1] J.-Y. Han and J.-K. Ahn, "Study on the Characteristics of Media Environment of MRS", The Journal of The Korea Contents Society, vol. 10, no. 11, (2010).

[2] Y. Gil-Sang, "Smart-learning Technology Based on Mixed Reality", Journal of Ad anced Information Technology and Convergence(JAITC), vol. 9, no. 3, (2011).

[3] T.-E. Kim and B.-C. Kim, "A Study of Multimedia Exhibition based on Augmented", The Journal of The Korea Institute of Electronic Communication Sciences, vol. 7, no 3, (2012).

[4] I.-S. Eo, "Digital Media Application in Museum", The Jounnal of The Korea Contents Society, vol. 10, no. 9, (2010).

[5] L. Jong-gwan, P. Seung-eok, K. Jong-gyu and I. Hyeong-taek, "Philosophical Reflections on Convergence Technology in the Digital Cultural Industry", Research on Future Platforms for Digital Convergence II. Korea Information Society Development Institute, (2010) Decembêr

[6] S. Carliner, "Modeling Information for Three-Dimensional Space- Lessons Learned from Museum Exhibit Design", Models, Processes, and Techniques of Information Design, (2000).
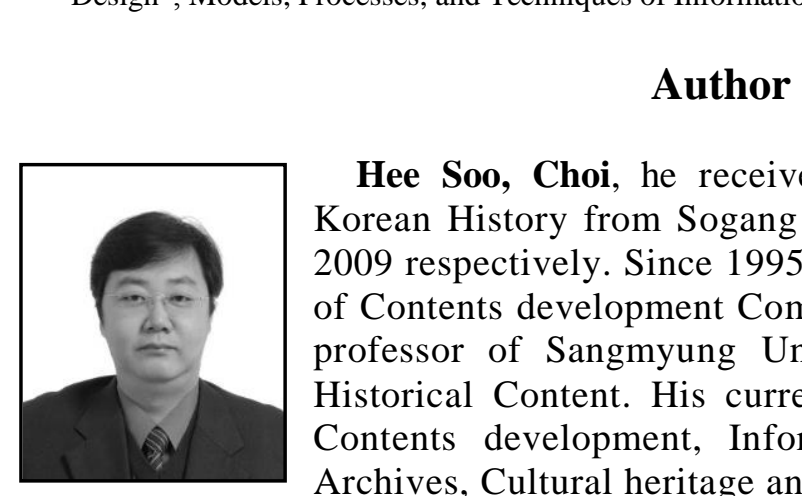

Hee Soo, Choi, he received B.A., M.A., and Ph.D degrees in Korean History from Sogang University, Korea in 1989, 1991, and 2009respectively. Since 1995, he has been a office worker and CEO of Contents development Company. And also since 2012, he was an professor of Sangmyung University, Department of History and Historical Content. His current research interests include Cultural Contents development, Information in Museum, Exhibition and Archives, Cultural heritage and Traditional Knowledge service.

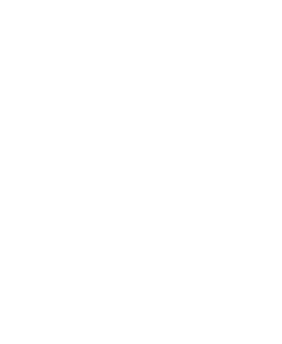


International Journal of Smart Home

Vol.8, No.1 (2014)

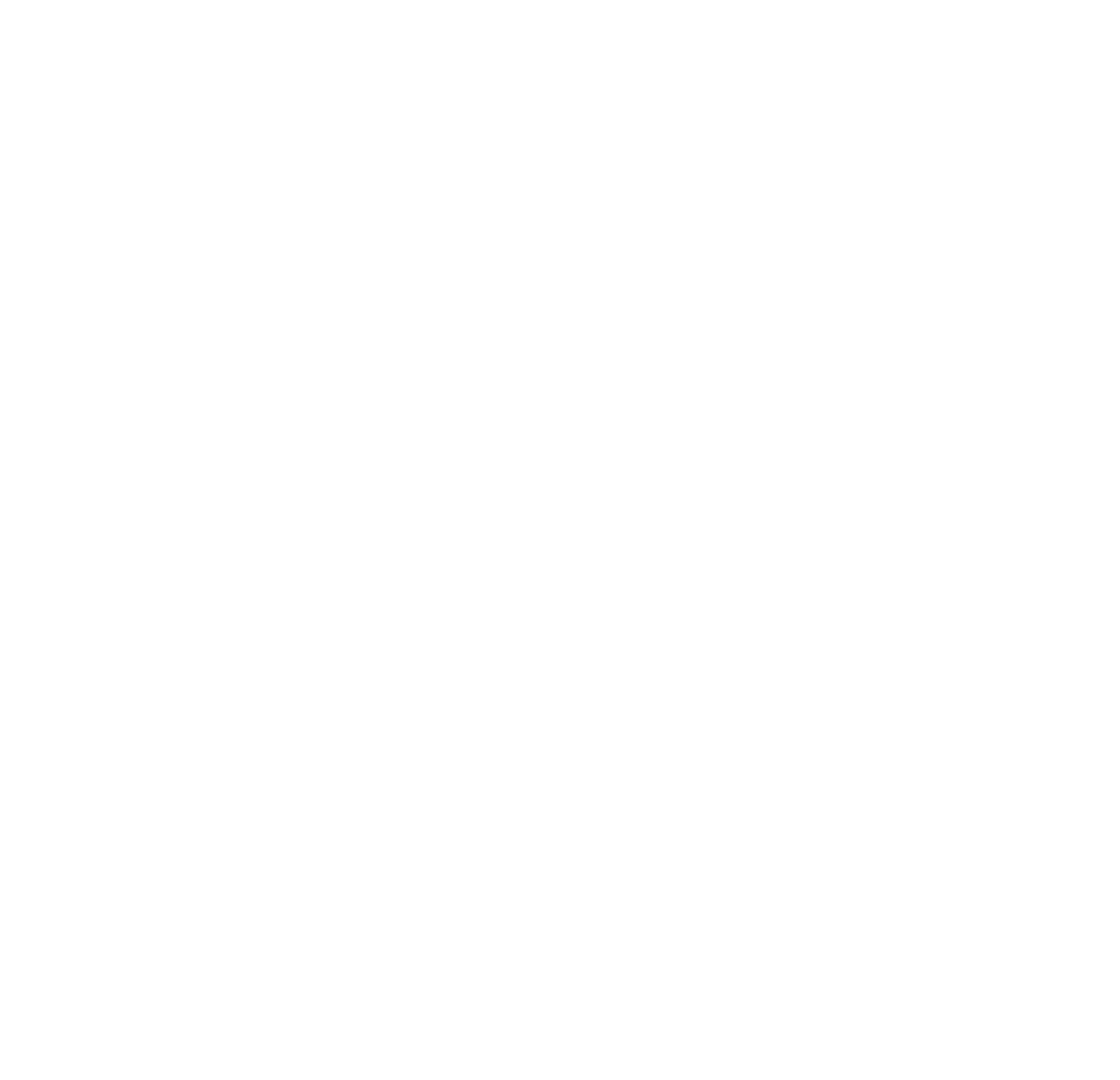

